Government departments during the last year. Experience has shown that low-temperature tars are particularly susceptible to a hydrogenation-cracking and some can be converted into motor spirit with a yield of nearly 100 per cent by volume, the tar acids being eliminated. Private concerns have accumulated much experience with the hydrogenation of coal and oils but their experience is not available. This adds to the interest of the Board's experiments on the mechanism of hydrogenation.

It has been shown that minute quantities of certain catalysts, for example, 0.067 per cent of some tin compounds, are effective. This emphasises the importance of the inorganic constituents of coal, and coal ashes are being examined spectroscopically to find whether coals exist containing germanium. Such observations stress the importance of the Physical and Chemical Survey of National Coal Resources, perhaps the most important branch of the Board's work, which now covers all the British coalfields. The rôle of the State in the prosecution of fuel research has its critics, but it must be allowed that private enterprise has failed to accumulate and provide the consumer with reliable information about the properties of its wares. Indeed it is a remarkable fact that the Survey has been established against the hostility of less enlightened coal-owners. Another notable item in the report is the publication of a collection of 365 analyses of commercial grades of coal raised in the South Yorkshire area. Actually this is a most useful publication; but in most industries, private concerns bear the cost of supplying the tests of their own commercial products.

The systematic survey not merely shows what is available underground but also suggests at times how the product can be improved by modifying the methods of working the coal. The Survey has confirmed the assertion that British coal seams are among the finest in the world and that with attention to the preparation for the market the product can meet any competition for quality.

Domestic fuel forms a big item in the national fuel bill, and work of general interest is reported. Many consumers can try for themselves the suggestion of making packets lined with aluminium foil containing coal slack. These, when placed on an open fire, hold together long enough to allow the coal to coke and then burn as a lump fuel.

These are a few items from the many investigations mentioned in the report, which covers practically the whole field of fuel technology. Certain investigations in university and other laboratories are also being supported financially, but on a reduced scale as a measure of national economy.

H. J. H.

\title{
Cosmic Rays
}

$\mathrm{K}^{\mathrm{o}}$ OLHÖRSTER has recently published a critical discussion of the nature of the cosmic rays (Phys. Z., Nov. 15). He points out that the cosmic rays may be investigated by the use of the ionisation chamber, the Geiger counter or the cloud chamber. The distribution of the ionisation in latitude shows variations which indicate that some at least of the rays are particles which can be deflected by the earth's magnetic field. A small azimuthal asymmetry has been detected which may indicate that an excess of the incident particles are positively charged.

Magnetic deflection experiments have not led to unambiguous results. The rays appear to be very fairly constant in intensity, though periodic variations of the order 2 per thousand may possibly occur during the sidereal or the solar day. The variation with barometer, due to absorption in the atmosphere, is well marked, and tends to obscure lesser variations. From time to time large bursts of ionisation are observed (Stösse) which are presumably of secondary origin. The curve connecting ionisation with height in the atmosphere has been repeatedly obtained up to the tropopause and some data exist at higher altitudes. The absorption of the radiation in water has been investigated. When the rays pass into a heavy absorbing medium, there is an anomalous variation in the absorption coefficient which indicates the production of a secondary radiation, and the production of such radiation is indicated by experiments with multiple coincidences of Geiger counters. The author concludes that the primary radiation is probably of corpuscular type. There is a long and useful, though incomplete, collection of references to the literature.

In the same number of the Physikalische Zeitschrift, Regener describes new measurements of cosmic rays in the stratosphere using his beautiful self-registering electroscope, while the Journal of the Franklin Institute of December 1933 contains an account of the photography of the Stösse by a Wilson chamber method. G. L. Locher arranges the Wilson chamber so that $j$ is fired automatically by the discharge of three non-collinear counter-tubes. The showers observed often appear to originate at two or more points and must apparently be initiated by nonionising secondary radiation, since their origins are frequently not collinear. There are also short tracks which are similar to those produced by recoil atoms from neutrons.

\section{Index of Business Activity}

$\mathrm{I}^{\mathrm{N}}$ a paper read before the Royal Statistical Society on January 16, Mr. Geoffrey Crowther described the "Index of Business Activity" which has recently been prepared by the Economist. Mr. Crowther pointed out that, up to the present, it has not been possible to measure statistically the amplitude of fluctuations in the general activity of the community. Indices of production are familiar in most countries and in the absence of a more suitable index, they are frequently used as indications of business activity, though they have obvious weaknesses for this purpose.

Productive industry is still the foundation for all economic wealth, but the superstructure of distribu. tion and service is yearly growing in size and importance. Moreover, it is a well-known economic phenomenon that the swings in activity in productive industry are considerably greater than the fluctuations of the economic life of the community as a whole. 
An index of business activity must therefore cast its net far wider than industrial production. It must take account not only of the rate at which goods are produced but also of the rates at which they are distributed, transported and sold.

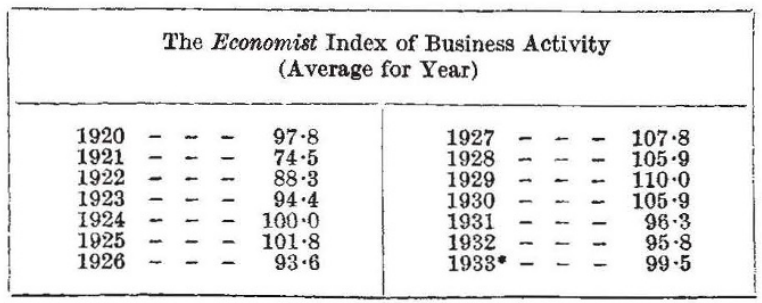

* Provisional; 11 months average.

The Economist "Index of Business Activity" is published monthly and is based on a weighted series of indices relating to employment, the iron and steel and cotton industries, imports of raw materials and non-ferrous metals, exports of manufactures, railway traffic, shipping movements, consumption of coal and electricity, postal receipts, bank clearings, building activity and the registration of motor vehicles.

\section{History of Mathematical Time}

$\mathrm{T}$ WO articles under the above title by G. Windred have been published in Isis, 19 and 20, in 1933. In the first the author traces the development of the concept of mathematical time from its origins with Napier, Barrow and Leibniz up to the theory of pure time of Sir William Rowan Hamilton. Within the short space of some thirty pages, the author gives an excellent account of Barrow's theory of mathematical time, which formed the basis of the time concept in Newtonian mechanics for more than two centuries. He traces the progress of the concept in the writings of Newton, Maclaurin and Kant, and concludes with a brief account of Hamilton's views on algebra as the science of pure time.

The second article is devoted to the history of time in the mathematical physics of the twentieth century. The author gives a brief account of the fundamental papers of H. A. Lorentz, Poincaré, Einstein and Minkowski concerning 'local' time, simultaneity of events and the synthesis of space and time into one whole in the special theory of relativity. He passes on to a relatively full account of Robb's theory of 'conical order' and concludes with brief references to the later work of Einstein, the system of time due to A. N. Whitehead, the views of Eddington, Vasiliev and Synge, and recent ideas on the atomic structure of time, due principally to Robert Lévy and Pokrowski. Here one misses any reference to the writings of $H$. Reichenbach, more particularly his "Philosophie der Raum-Zeit-Lehre", 1928, where a good deal of space is devoted to a discussion of the nature of time. Apart from this omission this part of the essay gives a clear and relatively full account of the changes brought about by the advent of the theory of relativity in our ideas of time. The last section of the essay gives a summary of the applications of the theory of time to mechanics and mathematical physics and of its implications for philosophy and psychology.
The essay can be highly recommended to anyone, whother mathematician, philosopher or physicist, who. needs a brief summary of the history of the concept of time from its origin to its latest develop. ments. It is well supplied with references and so can serve as a guide to anyone desirous of studying the question more completely than is possible in so short an essay.

\section{University and Educational Intelligence}

CAMBrIDGE.-The Buildings Syndicate recommends that the vacant site between the Museum of Archæology and Ethnology and the Botany School be assigned for an extension of the Museum, provided that this assignment be reconsidered if no permanent building is erected on the site within ten years.

The Council of the Senate recommends that a pension of $£ 430$ a year be granted to Prof. J. T. Wilson on his retirement from the professorship of anatomy.

The Faculty Board of Medicine recommends the establishment of a Marmaduke Shield scholarship in human anatomy of the value of $£ 100$ a year.

OXFORD.--In Congregation on March 3, the degree of D.Sc. was conferred on Charles K. Meek (Brasenose College), Government anthropologist in Nigeria, and author of three important works: "A Sudanese Kingdom" (1931); "Tribal Studies in Northern Nigeria" (1931); "The Northern Tribes of Nigeria" (1925).

ADult education is being exploited in the United States on a vast scale by the Federal Emergency Relief Administration as a means of providing work for unemployed teachers (including many unemployed persons who are potential though not professed teachers) and at the same time raising the standard of employability of the general mass of unemployed. Any person now on relief or urgently in need of a job, who is a college graduate or able to offer other proof of intellectual ability, is to be given an opportunity of employment as teacher. The scheme has six divisions, of which two are outside the field of adult education: teaching of 'illiterates', which is construed to mean education of adults up to sixth-grade level, general adult education, trade schools, training of physically disabled persons, reopening of rural schools closed for want of funds to pay teachers, and nursery schools in mining camps, mill villages and other places where children, especially children of the unemployed, are not being adequately cared for. It is anticipated that where the local organisation is slow in developing a general adult educational project, a competent unemployed seientific worker will work up a class for himself to teach, whereupon he will be enrolled as a paid instructor. The rates of payment have been revised, the former limit of 15 dollars a week having been withdrawn. The trade schools will provide employment for many engineers thrown out of work by industrial depression and the nursery schools will absorb some of the unemployed women trained in child psychology or kindergarten. School and Society of December 2 has an authoritative leading article describing the scheme. 